\title{
Patterns and predictors of patient and caregiver engagement in heart failure care: A multi-level dyadic study
}

\author{
Christopher S. Lee ${ }^{\mathrm{a}, *}$, Ercole Vellone ${ }^{\mathrm{b}}$, Karen S. Lyons ${ }^{\mathrm{a}}$, Antonello Cocchieri ${ }^{\mathrm{b}}$, \\ Julie T. Bidwell ${ }^{\mathrm{a}}$, Fabio D'Agostino ${ }^{\mathrm{b}}$, Shirin O. Hiatt ${ }^{\mathrm{a}}$, Rosaria Alvaro ${ }^{\mathrm{b}}$, \\ Harleah G. Buck ${ }^{\mathrm{c}}$, Barbara Riegel ${ }^{\mathrm{d}}$ \\ ${ }^{a}$ Oregon Health \& Science University, Portland, OR, USA \\ ${ }^{\mathrm{b}}$ University of Rome Tor Vergata, Rome, Italy \\ c The Pennsylvania State University, University Park, PA, USA \\ ${ }^{\mathrm{d}}$ University of Pennsylvania, Philadelphia, PA, USA
}

\section{A R T I C L E I N F O}

\section{Article history:}

Received 21 June 2014

Received in revised form 27 October 2014

Accepted 4 November 2014

\section{Keywords:}

Caregivers

Family

Heart failure

Self-care

\begin{abstract}
A B S T R A C T
Background: Heart failure is a burdensome clinical syndrome, and patients and their caregivers are responsible for the vast majority of heart failure care.

Objectives: This study aimed to characterize naturally occurring archetypes of patientcaregiver dyads with respect to patient and caregiver contributions to heart failure selfcare, and to identify patient-, caregiver- and dyadic-level determinants thereof.

Design: Dyadic analysis of cross-sectional data on patients and their caregivers.

Setting: Outpatient heart failure clinics in 28 Italian provinces.

Participants: 509 Italian heart failure patients and their primary caregivers.

Methods: Multilevel and mixture modeling were used to generate dyadic averages and incongruence in patient and caregiver contributions to heart failure self-care and identify common dyadic archetypes, respectively.

Results: Three distinct archetypes were observed. $22.4 \%$ of dyads were labeled as novice and complementary because patients and caregivers contributed to different aspects of heart failure self-care that was generally poor; these dyads were predominantly older adults with less severe heart failure and their adult child caregivers. $56.4 \%$ of dyads were labeled as inconsistent and compensatory because caregivers reported greater contributions to the areas of self-care most insufficient on the part of the patients; patients in these dyads had the highest prevalence of hospitalizations for heart failure in the past year and the fewest limitations to performing activities of daily living independently. Finally, 21.2\% of dyads were labeled as expert and collaborative because of high contributions to all aspects of heart failure self-care, the best relationship quality and lowest caregiver strain compared with the other archetypes; patients in this archetype were likely the sickest because they also had the worst heart failure-related quality of life.

Conclusion: Three distinct archetypes of dyadic contributions to heart failure care were observed that represent a gradient in the level of contributions to self-care, in addition to different approaches to working together to manage heart failure. Interventions and
\end{abstract}

\footnotetext{
* Corresponding author at: Oregon Health \& Science University, School of Nursing, Mail code: SN-2N, 3455 SW US Veterans Hospital Road, Portland, OR 97239-2941, USA. Tel.: +1 503494 4410; fax: +1 5034944456.

E-mail address: csleern@gmail.com (C.S. Lee).
} 
clinical programs that involve heart failure dyads should tailor strategies to take into consideration these distinct archetypes and their attributes.

(c) 2014 Elsevier Ltd. All rights reserved.

\section{What is already known about the topic?}

- Patients with heart failure vary considerably in their selfcare.

- Caregivers are thought to play a major role in supporting heart failure self-care.

\section{What this paper adds}

- There are three archetypes of patient and caregiver contributions to heart failure self-care.

- The three archetypes represent gradient in both the level of engagement in self-care and different approaches to working together to manage heart failure.

\section{Introduction}

Along with the worldwide growth of the elderly population, the number of adults affected by the clinical syndrome of heart failure will likely increase (Najafi et al., 2009). The costs associated with the treatment of heart failure are also projected to increase markedly over the next two decades (Heidenreich et al., 2013). Evidencebased therapies are essential to improve outcomes among adults with heart failure (McMurray et al., 2012); but, patients are responsible for the vast majority of heart failure care. That is, self-care of heart failure (i.e., patients' adherence to prescribed therapies and their ability to recognize and respond to symptoms effectively) is critical to the management of chronic heart failure (Moser et al., 2012; Riegel et al., 2011a,b). Patients with heart failure vary considerably in their self-care, however, and self-care is generally inadequate among adults with heart failure worldwide (Jaarsma et al., 2013). Thus, strategies that aim to enhance and support effective heart failure self-care behaviors are essential (Riegel et al., 2011a,b).

Caregivers are thought to play a major role in supporting heart failure self-care; but, the science supporting this claim is quite limited (Buck et al., 2014). There are many ways in which caregivers can be incorporated into heart failure care planning and contribute to heart failure self-care. These include helping patients prepare low-sodium meals, develop systems for taking all medications as prescribed and practice what to do when heart failure symptoms occur, as well as directly monitoring for signs and symptoms of worsening heart failure; it is also recommended that heart failure caregivers be included in all appointments with healthcare provider (Riegel et al., 2009). Exactly how this works in practice, however, is not well understood. What is known is that heart failure patients and caregivers who take a collaborative approach to heart failure management have better outcomes like better caregiver quality of life [QOL] (Pressler et al., 2013) and less caregiver strain (Hwang et al., 2011; Luttik et al., 2007a,b), whereas a gap between the patient's and caregiver's appraisal of symptoms and respective contributions to care leads to inadequate symptom management (Janssen et al., 2012; Quinn et al., 2010; Retrum et al., 2013; Rohrbaugh et al., 2008; Sebern and Riegel, 2009). Thus, how patient-caregiver dyads function together in their contributions to care is an important consideration in the overall management of heart failure. Although a typology of self-care has been identified previously among heart failure patients (Dickson et al., 2008; Riegel et al., 2011a,b), common and distinct archetypes of patient-caregiver dyads, their attributes, and their determinants are still being explored (Buck et al., 2013).

Accordingly, this study aimed to identify and characterize archetypes (i.e., naturally occurring patterns) of heart failure patient-caregiver dyads with respect to patient and caregiver contributions to self-care. This study also aimed to identify additional patient-, caregiver- and dyadic-level factors that were helpful in determining which of the observed archetypes the dyad was most likely to embody.

\section{Methods}

\subsection{Study design}

This was a secondary analysis of cross-sectional data collected during a study of Italian heart failure patients and their caregivers (Cocchieri et al., 2014; Vellone et al., 2014). The aims of the original study were to describe and identify socio-demographic and clinical determinants of self-care behaviors among Italian adults with heart failure. In brief, 1192 heart failure patients were enrolled from outpatient centers in 28 Italian provinces. Participants were 18 years of age or greater and had a confirmed diagnosis of heart failure; in accordance with evidencebased guidelines (McMurray et al., 2012), all diagnoses were made by treating cardiologists based on echocardiographic evidence confirmed with clinical evidence (i.e., signs of heart failure like edema or elevated filling pressures and common symptoms of heart failure like dyspnea). Patient participants also had no acute cardiovascular events in the preceding 3 months by inclusion criteria. Participants were excluded solely on the basis of obvious dementia. Caregivers in this study were defined as the unpaid person (inside or outside the family) who provides the most informal care to a person affected by heart failure, was identified as such by the patient and designated by the heart failure patient as the primary caregiver. Caregivers in this study were designated by the heart failure patient as the primary caregiver, accompanied the patient to the enrollment visit and were willing to participate in the study. All questionnaire data were 
collected in person in a private space by trained nurse research assistants. This analysis was conducted using the subset of data available on both the patient with heart failure and his/her caregiver, and is complementary to the aims of the parent study. The Strengthening the Reporting of Observational Studies in Epidemiology Statement was used to guide our reporting of this observational study (von Elm et al., 2007).

\subsection{Ethical approval}

This study complied with the Declaration of Helsinki, ethics committees at each site approved the research protocol, and informed consent was obtained from all participants. To ensure compliance with de-identified data handling procedures, the secondary analysis presented in this paper was also reviewed by the Institutional Review Board of the first and several other authors; the analysis was deemed as being exempt for human subjects review as all data were appropriately de-identified.

\subsection{Measurement}

All measures included on the patient and caregiver questionnaires had been previously translated and validated in Italian except where noted. Self-reported sociodemographics (e.g., age, gender, income, education, relationship between the patient and caregiver) were collected via an investigator-developed survey; an additional item on relationship quality ( 1 (worst) to 5 (best)) was included on the patient survey only. Clinical information on the patients (e.g., duration of illness, hospitalization for heart failure within the last year, and New York Heart Association functional class) was abstracted from the medical record.

\subsection{Patient and caregiver contributions to self-care}

Patient-reported self-care of heart failure was measured using the Italian version of the Self-Care of Heart Failure Index v6.2 [SCHFI] which was developed as part of the parent study (Vellone et al., 2013a,b). The SCHFI has 22 items that capture self-care maintenance (daily routine behaviors), management (symptom recognition and response behaviors), and confidence (confidence in the ability to engage effectively in self-care). Standardized scores are calculated for each scale (range 0-100) with higher scores indicating better self-care. Factor score determinacy reliability coefficients were between 0.78 and 0.90 for the three scales in this patient sample (Vellone et al., 2013a,b).

Caregiver-reported contributions to heart failure care was measured using the Italian version of the Caregiver Contribution to Self-care of Heart Failure Index [CC-SCHFI], a measure derived from the SCHFI that was developed as part of the parent study (Vellone et al., 2013a,b). The CC-SCHFI measures the contribution of caregivers to the self-care maintenance and self-care management of heart failure patients, as well as their confidence in their ability to contribute to the patients' self-care. The CC-SCHFI addresses how often the caregiver recommends to the patient that she/ he engage in the specific self-care behaviors, or how often the caregiver engages in the behaviors for the patient because they are unable to themselves. Standardized scores for each scale range from 0 to 100 with higher scores indicating greater caregiver contributions to heart failure self-care. Factor score determinacy reliability coefficients were between 0.65 and 0.90 for the three scales in this sample of caregivers (Vellone et al., 2013a,b).

\subsection{Determinants of dyadic contributions to self-care}

Patient- and caregiver-level determinants of dyadic contributions to heart failure self-care were measured including patient comorbidities, cognitive function, activities of daily living and physical and emotional QOL, as well as caregiver QOL and strain. Details on these measures are presented in Table 1.

\subsection{Statistical analysis}

First, the statistical program Hierarchical Linear and Nonlinear Modeling v7 (Skokie, IL) was used to generate patient-caregiver dyadic averages and incongruence scores (i.e., the degree to which the patient contributes more than the caregiver and vice versa) on heart failure self-care maintenance, management and confidence. The use of multilevel modeling to control for the interdependent nature of dyadic data has been well-described elsewhere (Lyons et al., 2002). In brief, our approach accounted for measurement error and interdependence of data at the item level, and results in empirical Bayes

Table 1

Patient and caregiver determinants of dyadic contributions to heart failure self-care.

\begin{tabular}{|c|c|c|c|}
\hline Concept & Measure & Range & Notes \\
\hline Patient comorbidities & $\begin{array}{l}\text { Charlson comorbidity index } \\
\text { (Charlson et al., 1987) }\end{array}$ & $0-30$ & Higher scores indicate greater risk of mortality. \\
\hline Patient cognitive function & $\begin{array}{l}\text { Mini mental state examination } \\
\text { (Folstein et al., 1975) }\end{array}$ & $0-30$ & Higher scores indicate better cognitive function. \\
\hline Patient activities of daily living & $\begin{array}{l}\text { Barthel index (Mahoney and } \\
\text { Barthel, 1965) }\end{array}$ & $0-100$ & $\begin{array}{l}\text { Lower scores indicate greater disability in activities } \\
\text { of daily living. }\end{array}$ \\
\hline $\begin{array}{l}\text { Patient physical and emotional } \\
\text { quality of life }\end{array}$ & $\begin{array}{l}\text { Minnesota living with heart failure } \\
\text { questionnaire (Rector et al., 1993) }\end{array}$ & $\begin{array}{l}\text { Physical } 0-40 \\
\text { Emotional } 0-25\end{array}$ & $\begin{array}{l}\text { Higher scores indicate worse quality of life; } \alpha=0.86 \\
\text { (physical) and } 0.79 \text { (emotional) in this sample. }\end{array}$ \\
\hline Caregiver quality of life & $\begin{array}{l}\text { SF-12 health survey } \\
\text { (Ware et al., 1996) }\end{array}$ & $\begin{array}{l}\text { Physical 0-100 } \\
\text { Mental 0-100 }\end{array}$ & $\begin{array}{l}\text { Higher scores indicate better quality of life; } \alpha=0.80 \\
\text { (physical) and } 0.67 \text { (mental) in this sample. }\end{array}$ \\
\hline Caregiver strain & $\begin{array}{l}\text { Caregiver burden inventory } \\
\text { (Novak and Guest, 1989) }\end{array}$ & $0-96$ & $\begin{array}{l}\text { Higher scores indicate greater caregiver strain; } \\
\alpha=0.96 \text { in this sample. }\end{array}$ \\
\hline
\end{tabular}


estimates of both the dyadic average (i.e., how they are doing together) and the incongruence (i.e., the magnitude and direction of the gap between the two members of the dyad) in self-care maintenance, management, and confidence were generated. We then regressed and plotted caregiver strain and patient physical QOL on the dyadic average and incongruence scores, as well as the interaction between dyadic average, of maintenance and management, respectively; this step served as preliminary evidence that both the dyadic average and incongruence scores are important to consider in relation to well-known caregiver and patient outcomes in heart failure.

Second, we identified distinct and naturally occurring archetypes of dyadic contributions to heart failure selfcare using latent class mixture modeling in Mplus v7.11 (Los Angeles, CA, USA). Latent class mixture modeling is a robust clustering technique that results in the identification of previously unobserved subgroups. For this analysis, dyadic averages and incongruence scores of both maintenance and management behaviors were included in our latent class mixture modeling. The Lo-Mendell-Rubin adjusted likelihood ratio test, model convergence (entropy near 1.0 ), the size of the observed profiles (not less than $5 \%$ of the sample), and posterior probabilities (average posterior probabilities for most likely class near 1.0) were used to assess the performance of alternative models (e.g., 3 vs. 2 profiles) (Ram and Grimm, 2009).

Third, comparative statistics ( $F$-statistics from analysis of variance and $\chi^{2}$ ) were used to compare factors among the observed archetypes that were labeled according to key differentiating characteristics of the dyads' contributions to self-care. Multinomial regression was used to identify adjusted determinants of the observed archetypes; all determinants with univariate significance of $\leq 0.30$ were included in multivariate modeling. Results are reported in adjusted relative risk ratios (RRR) and 95\% confidence intervals (CI)s and were computed using Stata MP v13 (College Station, TX, USA).

\section{Results}

The characteristics of the sample are presented in Table 2. On average, patients were approximately 19 years older than their caregivers. Just under half of the patients and slightly more than half of the caregivers were women. Patients had been living with heart failure for an average of just under 5 years and a slight majority had New York Heart Association class I/II heart failure. A minority of caregivers lived with the patient; a slight majority of caregivers were adult children of the patients with heart failure.

\subsection{Averages and gaps in contributions to care}

The raw results of hierarchical modeling of dyadic contributions to self-care and incongruence are presented in the Supplementary Table. In brief, there was considerable variability in dyadic averages of maintenance, management and confidence and in incongruence between patient and caregiver contributions to self-care; caregivers generally reported greater contributions to self-care than patients. There were both direct and moderating effects of the average level of engagement and incongruence in

Table 2

Characteristics of heart failure patients $(n=509)$ and their caregivers $(n=509)$.

\begin{tabular}{|c|c|c|}
\hline & \multicolumn{2}{|c|}{ Mean \pm standard deviation, or $n(\%)$} \\
\hline & $\begin{array}{l}\text { Patients with } \\
\text { Heart Failure }\end{array}$ & $\begin{array}{l}\text { Primary } \\
\text { Caregivers }\end{array}$ \\
\hline Age (in years) & $75.6 \pm 10.7$ & $56.9 \pm 14.8$ \\
\hline Gender (\% female) & $227(44.6 \%)$ & $225(52.2 \%)$ \\
\hline Education (professional/high school/university) & $125(24.7 \%)$ & $248(51.7 \%)$ \\
\hline Married & $284(55.8 \%)$ & $316(73.2 \%)$ \\
\hline Currently employed (\%) & $57(11.2 \%)$ & $272(56.6 \%)$ \\
\hline Living with patient (\%) & & $183(37.3 \%)$ \\
\hline \multicolumn{3}{|l|}{ Relationship with patient } \\
\hline Spouse & - & $142(34.0 \%)$ \\
\hline Adult child of patient & - & $223(53.4 \%)$ \\
\hline Other family or friend & - & $53(12.6 \%)$ \\
\hline \multicolumn{3}{|l|}{ New York Heart Association functional class } \\
\hline I or II & $283(55.8 \%)$ & - \\
\hline III or IV & $224(44.2 \%)$ & - \\
\hline Months with heart failure & $57.1 \pm 47.1$ & - \\
\hline Hospitalized for heart failure in last year & $286(56.2 \%)$ & - \\
\hline Cognitive impairment (MMSE $<27$ ) & $200(39.8 \%)$ & - \\
\hline Charlson comorbidity index & $3.0 \pm 1.3$ & - \\
\hline Heart failure-specific physical quality of life $\mathrm{a}^{\mathrm{a}}$ & $21.7 \pm 8.8$ & - \\
\hline Heart failure-specific emotional quality of life $\mathrm{a}^{\mathrm{a}}$ & $11.7 \pm 5.8$ & - \\
\hline General physical quality of life $\mathrm{e}^{\mathrm{b}}$ & - & $46.3 \pm 8.8$ \\
\hline General mental quality of life $\mathrm{b}^{\mathrm{b}}$ & - & $47.9 \pm 9.7$ \\
\hline Caregiver strain & - & $28.5 \pm 22.6$ \\
\hline Hours of caregiving per day & - & $7.6 \pm 7.2$ \\
\hline
\end{tabular}

Abbreviations: MMSE $=$ mini mental state examination.

a Minnesota Living with Heart Failure Questionnaire.

b SF-12 health survey 
self-care maintenance on caregiver strain (Supplementary Figure). Similarly, there were both direct and interactive effects of the average level of engagement and incongruence in self-care management behaviors on patient physical QOL (Supplementary Figure). Simply put, caregiver strain and patient physical QOL are a function of both dyadic averages and incongruence in self-care maintenance and management, respectively. Thus, both dyadic averages and incongruence scores were included in our archetype identification.

\subsection{Identifying and characterizing heart failure dyadic archetypes}

Three distinct archetypes of dyadic contributions to heart failure self-care were identified (entropy $=0.77$; posterior probabilities exceed 0.87; Lo-Mendell-Rubin test $=177.16, p=0.035$; all favoring a good model solution). Archetypes were labeled according to dominant characteristics of the dyad's contributions to heart failure self-care (Table 3). Similarities and differences among the archetypes regarding their contributions to heart failure self-care are also graphically depicted in Fig. 1. Additional patient, caregiver, and dyadic attributes of the observed archetypes of contributions to heart failure self-care are presented in Table 4 (unadjusted) and in Table 5 (adjusted differences).

First, a "novice and complementary" heart failure dyadic archetype ( $n=114,22.4 \%)$ had the lowest dyadic averages of self-care maintenance and confidence (i.e., novice self-care). Each member of these dyads was engaged in different aspects of heart failure self-care. Specifically, patients in this archetype reported greater contributions to self-care maintenance than did their caregivers, and in contrast caregivers reported greater contributions than the patients to self-care management (i.e., complementary contributions). Older patient age, better emotional QOL, fewer limitations to the patient's activities of daily living, and dyads predominantly comprised of patients and their adult child caregivers were additional attributes of the novice and complementary dyadic archetype of contributions to heart failure self-care.

Second, an "inconsistent and compensatory" heart failure dyadic archetype ( $n=287,56.4 \%)$ had higher levels of contributions to self-care maintenance, but similar levels of contributions to self-care management and confidence as those in the novice and complementary archetype (i.e., inconsistent self-care). Caregivers in this archetype reported greater contributions than the patients to the aspects of self-care that were most deficient; that is, the incongruence between caregiver and patient contributions were greatest in this archetype with respect to self-care management and confidence (i.e., compensatory contributions). Also, patients in the inconsistent and compensatory dyadic archetype of contributions to heart failure self-care had the fewest limitations in performing activities of daily living and more of them had hospitalizations for heart failure in the past year, compared with the other archetypes.

Third, an "expert and collaborative" heart failure dyadic archetype ( $n=108,21.2 \%$ ) had the highest dyadic averages of contributions to self-care maintenance, management and confidence (i.e., expert self-care). Caregivers in this archetype reported greater contributions to all aspects of self-care than patients, but particularly in maintenance. Patients of this archetype also had the worst mental and physical QOL and the greatest limitations to activities of daily living compared with the other archetypes; they were likely the sickest patients. Patients in this dyadic archetype of contributions to heart failure self-care also reported the best relationships with their caregivers, and caregiver strain was lowest compared with the other archetypes (i.e., collaborative nature of contributions).

\section{Discussion}

We know that better self-care is associated with more favorable outcomes among adults with heart failure. We also know from the heart failure-specific and broader caregiving literature that collaborative approaches to chronic illness have positive outcomes (Retrum et al., 2013; Rohrbaugh et al., 2008; Sebern and Riegel, 2009). In this sample of 509 community-dwelling Italian adults with chronic heart failure and their primary caregivers, we observed three distinct archetypes of patient and caregiver contributions to heart failure self-care that help further our understanding of how heart failure dyads work together. We observed a gradient in heart failure self-care ability that ranges from novice to expert across the archetypes. Notably, we also observed three different forms of collaboration between patients and their caregivers across the archetypes that are driven partly by perceived need and partly by the characteristics of the members of the heart failure dyad. This is the first quantitative description

Table 3

Archetypes of dyadic contributions to heart failure self-care

\begin{tabular}{|c|c|c|c|c|}
\hline Aspect of heart failure self-care & $\begin{array}{l}\text { Novice \& } \\
\text { complementary }\end{array}$ & $\begin{array}{l}\text { Inconsistent \& } \\
\text { compensatory }\end{array}$ & $\begin{array}{l}\text { Expert \& } \\
\text { collaborative }\end{array}$ & F-statistic, $p$-value \\
\hline Self-care maintenance dyadic average & $46.0 \pm 4.0$ & $54.3 \pm 3.4$ & $63.8 \pm 4.3$ & $626.3,<0.0001$ \\
\hline Incongruence in maintenance & $-4.6 \pm 3.8$ & $3.4 \pm 3.1$ & $10.0 \pm 3.4$ & $542.0,<0.0001$ \\
\hline Self-care management dyadic average & $50.2 \pm 8.9$ & $49.2 \pm 8.9$ & $61.5 \pm 9.1$ & $77.8,<0.0001$ \\
\hline Incongruence in management & $5.9 \pm 3.2$ & $6.4 \pm 3.3$ & $5.3 \pm 3.5$ & $4.6,=0.0101$ \\
\hline Self-care confidence dyadic average & $50.0 \pm 8.8$ & $52.0 \pm 11.2$ & $65.8 \pm 12.8$ & $72.8,<0.0001$ \\
\hline Incongruence in confidence & $3.2 \pm 9.1$ & $5.3 \pm 9.3$ & $5.2 \pm 9.2$ & $2.2,=0.1093$ \\
\hline
\end{tabular}

Note: Negative values of incongruence indicate that patient reported greater contributions to self-care than their caregiver; positive values indicate that caregivers report greater contributions to self-care than the patients. 


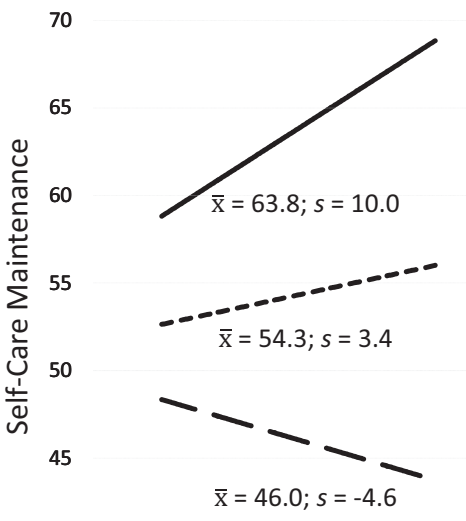

40

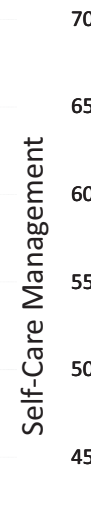

40

70

Patient Caregiver

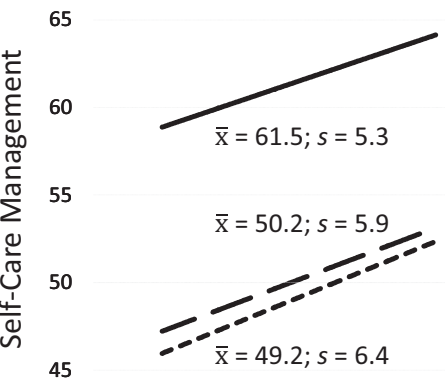

Patient
40

Caregiver

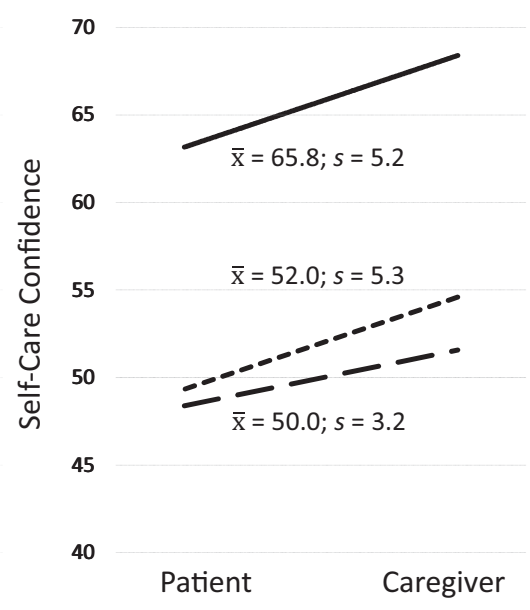

Expert \& Collaborative

Fig. 1. Heart failure patient and primary caregiver contributions to self-care are depicted for each observed archetype. The average of each aspect of self-care between the patient and caregiver $(\bar{X})$ helps us understand the dyads overall engagement in self-care, and the incongruence ( $s$ ) helps us understand the differences and similarities between the patients' and the caregivers' relative contributions across aspects of self-care.

Table 4

Differences among archetypes of dyadic contributions to heart failure self-care.

\begin{tabular}{|c|c|c|c|c|}
\hline Characteristics & $\begin{array}{l}\text { Novice \& } \\
\text { complementary }\end{array}$ & $\begin{array}{l}\text { Inconsistent \& } \\
\text { compensatory }\end{array}$ & $\begin{array}{l}\text { Expert \& } \\
\text { collaborative }\end{array}$ & $F / \chi^{2}, p$-value \\
\hline \multicolumn{5}{|l|}{ Patient-level } \\
\hline Age & $77.2 \pm 10.1$ & $75.4 \pm 10.5$ & $74.4 \pm 11.6$ & $1.99,0.138$ \\
\hline Female gender & $50(43.9 \%)$ & $122(42.5 \%)$ & $55(50.9 \%)$ & $2.28,0.319$ \\
\hline Higher Education & $40(26.6 \%)$ & 74 (25.9\%) & $21(19.6 \%)$ & $1.90,0.387$ \\
\hline Family income $<€ 1000$ & $37(33.9 \%)$ & $109(38.8 \%)$ & $48(44.4 \%)$ & $2.52,0.283$ \\
\hline Employed & $12(1.05 \%)$ & 33 (11.5\%) & $12(11.1 \%)$ & $0.08,0.961$ \\
\hline NYHA III/IV & $46(40.4 \%)$ & 125 (43.9\%) & $53(49.1 \%)$ & $1.74,0.419$ \\
\hline Months with heart failure & $50.8 \pm 38.8$ & $55.4 \pm 44.5$ & $68.3 \pm 59.1$ & $4.13,0.017$ \\
\hline Hospitalized last year & $56(49.1 \%)$ & $171(59.6 \%)$ & $59(54.6 \%)$ & $3.76,0.153$ \\
\hline MMSE & $23.6 \pm 6.6$ & $23.3 \pm 6.9$ & $23.3 \pm 6.4$ & $0.06,0.938$ \\
\hline Charlson index & $2.9 \pm 1.2$ & $3.1 \pm 1.4$ & $3.1 \pm 1.2$ & $0.93,0.394$ \\
\hline Heart failure physical QOL & $20.2 \pm 8.7$ & $21.8 \pm 8.6$ & $23.2 \pm 9.4$ & $3.09,0.047$ \\
\hline Heart failure emotional QOL & $10.4 \pm 6.2$ & $11.6 \pm 5.4$ & $13.3 \pm 6.0$ & $7.13,0.001$ \\
\hline Barthel index & $83.2 \pm 18.8$ & $88.9 \pm 20.7$ & $81.6 \pm 21.6$ & $3.29,0.038$ \\
\hline \multicolumn{5}{|l|}{ Caregiver-level } \\
\hline Age & $55.6 \pm 15.7$ & $57.8 \pm 14.8$ & $56.2 \pm 13.7$ & $1.00,0.369$ \\
\hline Female gender & $59(55.7 \%)$ & $111(46.3 \%)$ & $36(42.4 \%)$ & $3.87,0.145$ \\
\hline Higher Education & $65(58.0 \%)$ & $138(50.2 \%)$ & $45(48.4 \%)$ & $2.46,0.292$ \\
\hline Employed & $65(58.6 \%)$ & $153(55.4 \%)$ & $54(57.55)$ & $0.35,0.838$ \\
\hline Daily caregiving hours & $7.5 \pm 7.2$ & $7.4 \pm 7.4$ & $7.6 \pm 6.8$ & $0.02,0.979$ \\
\hline Physical QOL & $46.8 \pm 9.1$ & $46.1 \pm 8.7$ & $46.0 \pm 9.0$ & $0.29,0.751$ \\
\hline Mental QOL & $48.0 \pm 10.1$ & $47.3 \pm 9.4$ & $49.7 \pm 9.7$ & $2.36,0.096$ \\
\hline Caregiver strain & $28.2 \pm 25.1$ & $30.1 \pm 22.8$ & $24.0 \pm 18.3$ & $2.60,0.075$ \\
\hline \multicolumn{5}{|l|}{ Dyad-level } \\
\hline Relationship quality & $4.2 \pm 1.2$ & $4.2 \pm 1.0$ & $4.6 \pm 0.9$ & $5.03,0.007$ \\
\hline Live together & $45(39.8 \%)$ & $103(36.8 \%)$ & $35(35.7 \%)$ & $0.44,0.801$ \\
\hline \multicolumn{5}{|l|}{ Relationship type } \\
\hline Spousal & $27(26.7 \%)$ & $88(37.8 \%)$ & $27(32.1 \%)$ & \\
\hline Adult-child & $63(62.4 \%)$ & $115(49.4 \%)$ & $45(53.6 \%)$ & $5.30,0.258$ \\
\hline Other family/friend & $11(10.9 \%)$ & $30(12.9 \%)$ & $12(14.3 \%)$ & \\
\hline
\end{tabular}

Abbreviations: MMSE = mini mental state examination; NYHA = New York Heart Association; QOL = quality of life.

of heart failure dyadic archetypes in general, and with respect to dyadic contributions to self-care in particular.

Novice and complementary dyads worked together by assuming distinct, but complementary roles. Patients were more involved in their daily routine self-care behaviors and caregivers assumed a greater role in responding to heart failure symptoms. In the context of older patient age and a predominance of adult-child caregivers, such a complementary approach to heart failure self-care suggests that patient independence in routine self-care is valued. The novice and complementary dyad may not be driven to engage in higher levels of heart failure self-care 
Table 5

Adjusted characteristics of archetypes of dyadic contributions to heart failure self-care.

\begin{tabular}{|c|c|c|}
\hline & $\begin{array}{l}\text { Novice \& complementary } \\
\text { Dyadic archetype } \\
\text { RRR }(95 \% \mathrm{CI}), p \text {-value }\end{array}$ & $\begin{array}{l}\text { Expert \& collaborative } \\
\text { Dyadic archetype } \\
\text { RRR }(95 \% \mathrm{CI}), p \text {-value }\end{array}$ \\
\hline \multicolumn{3}{|l|}{ Patient-level factors } \\
\hline Age (years) & 1.030 (1.001-1.060), 0.044 & $0.991(0.959-1.024), 0.588$ \\
\hline \multicolumn{3}{|l|}{ Income (referent is $\leq € 1000$ ) } \\
\hline Income (€1001-2000) & $1.676(0.898-3.125), 0.105$ & $0.808(0.431-1.518), 0.508$ \\
\hline Income $(>€ 2000)$ & $2.080(0.882-4.903), 0.094$ & $0.266(0.080-0.879), 0.030$ \\
\hline Patient emotional QOL & $0.936(0.883-0.991), 0.023$ & $1.146(1.076-1.221),<0.001$ \\
\hline Barthel index & 1.019 (1.002-1.036), 0.035 & 1.017 (0.999-1.034), 0.052 \\
\hline Months with heart failure & $0.996(0.990-1.002), 0.210$ & 1.004 (0.998-1.010), 0.159 \\
\hline Hospitalization last year & $0.853(0.487-1.494), 0.578$ & $1.003(0.526-1.912), 0.994$ \\
\hline \multicolumn{3}{|l|}{ Caregiver-level factors } \\
\hline Female gender & 0.631 (0.369-1.079), 0.093 & $1.463(0.802-2.672), 0.215$ \\
\hline Higher Education & 0.745 (0.419-1.326), 0.317 & $0.635(0.342-1.178), 0.150$ \\
\hline Mental QOL & 0.988 (0.957-1.020), 0.457 & $1.042(1.005-1.081), 0.027$ \\
\hline Caregiver strain & $0.996(0.983-1.010), 0.556$ & 0.988 (0.971-1.005), 0.153 \\
\hline \multicolumn{3}{|l|}{ Dyad-level factors } \\
\hline Relationship quality & $1.003(0.791-1.272), 0.978$ & 1.460 (1.045-2.038), 0.027 \\
\hline \multicolumn{3}{|l|}{ Relationship type $^{\mathrm{a}}$} \\
\hline Adult Child-Parent & 2.152 (1.180-3.925), 0.012 & 1.352 (0.684-2.672), 0.385 \\
\hline Other Family/Friend & 0.064 (0.307-2.436), 0.783 & $1.244(0.485-3.193), 0.649$ \\
\hline
\end{tabular}

because the impact of heart failure and its treatment has not yet taken a toll on patients' QOL. That is, patient in this dyadic archetype may not be as sick with heart failure compared with patients in the other dyadic archetypes. Thus, there is a low perceived need and/or desire for caregivers to be more involved in self-care maintenance. Caregivers, in these dyads, seemingly become more involved as symptoms occur by supporting the patients in their response to symptoms and/or working with the patients to recognize and respond to signs and symptoms of worsening heart failure.

Inconsistent and compensatory dyads are more involved in self-care maintenance behaviors compared with the novice and complementary archetype, and caregivers report greater contributions to all aspects of heart failure self-care than the patients. Despite greater contributions to self-care maintenance by the patient and caregiver, this type of dyad performs poorly in self-care management. Perhaps due to a higher perceived need or as an attempt to keep patients from being hospitalized for heart failure again, the work of the caregiver in this type of dyad is centered on compensating for the recognition and response to symptoms that the patient may not be fully capable of performing independently. The compensatory nature of the work of this type of dyad is also associated with greater caregiver strain. Thus, this type of dyad may be most vulnerable to poor caregiver outcomes.

Expert and collaborative dyads stand apart from the other two archetypes by having the greatest engagement in all aspects of self-care and the greatest relationship quality. Caregivers are contributing to self-care maintenance and management more than patients, however, particularly in the area of routine care behaviors where the gap is substantial. Patients and caregivers in this type of dyad seem to recognize and respond to heart failure symptoms at a similarly high level possibly reflecting a shared appraisal of the patient's needs and the seriousness of symptoms when they occur. Patient QOL was worse in this archetype compared with the other two indicating that heart failure was likely more severe in this group. Given that caregiver strain was lowest in this type of dyad despite significant contributions to self-care and the worst patient QOL, the high reports of relationship quality indicate the collaboration in this type of dyad is likely based on cooperation, shared decision-making and a mutual understanding of how best to work together (Rohrbaugh et al., 2008; Sebern and Riegel, 2009; Sebern and Woda, 2012). Communication problems are a known source of stress for heart failure families (Dalteg et al., 2011; Luttik et al., 2007a,b), and positive communication is associated with greater confidence in heart failure self-care (Sebern and Riegel, 2009). Thus, it may be that better relationship quality and effective communication mitigates the influence that poor patient QOL would otherwise have on caregiver strain in this type of heart failure dyad.

Our findings fit within the context of a known typology of heart failure self-care. Dickson and colleagues first characterized a novice/inconsistent/expert typology of heart failure self-care in a small sample of non-elders (Dickson et al., 2008). The novice to expert typology of heart failure self-care was later validated in a large sample of older adults by Riegel and colleagues (Riegel et al., 2011a,b). Our findings build upon this prior work in that we have observed three heart failure dyadic archetypes of self-care and have similarly identified a gradient in the 
dyad's self-care ability that ranges from novice to expert. Importantly, our findings also fit within the context of what we know about how patients and their caregivers work together in the context of chronic illness. For example, Berg and Upchurch described how support (i.e., caregiver providing support to the patient) and collaboration (e.g., joint involvement and decision-making) vary among chronic illness dyads (Berg and Upchurch, 2007). Moreover, Buck and colleagues recently identified a typology in a small qualitative sample of heart failure patients and their spouses: the typology included patientoriented (patients perform the majority of self-care), caregiver-oriented (caregivers perform the majority of self-care), collaboratively-oriented (the pair works and makes decisions together), and complementary-oriented dyads (each member is engaged in different aspects of heart failure self-care) (Buck et al., 2013). Reflecting several elements of the heart failure dyad typologies of self-care, our findings provide additional insight into the various ways that patients and their caregivers collaborate to manage heart failure. Finally, our findings provide evidence that the assessment and support of heart failure self-care needs to be tailored according to how well the patient and caregiver are currently working together to manage heart failure.

\subsection{Implications for research and practice}

The next step in this line of inquiry is to examine the stability of the archetypes across time. Whether novice/ complementary dyads develop into inconsistent/compensatory or expert/collaborative is currently unknown. If these archetypes are stable over time then early supportive interventions for novice/complementary and inconsistent/ compensatory dyads may result in fewer emergent hospitalizations and their associated impact on QOL and cost. If, however, the archetypes progress from novice to expert as in other like typologies then educational interventions may potentiate this progression resulting in better patient and caregiver outcomes. Additionally, it will be necessary to test relationships between the dyadic archetypes of contributions to heart failure self-care on outcomes such as change in QOL or event-free survival using longitudinal designs as opposed to the crosssectional design of this study.

These findings also have important implications for practice. First, caregivers generally report greater contributions to self-care than patients. Moreover, heart failure dyads work together in different ways to manage heart failure. Thus, caregivers should be included in all educational sessions, and how the heart failure dyad works together should be taken into consideration so that they can benefit from nursing's expertise in assessing, teaching and coaching effective heart failure self-care. Second, it may be recognized without actually measuring patient or caregiver contributions to self-care which particular archetype fits a heart failure dyad. For example, an older patient with an adult child caregiver who has few limitations to activities of daily living and good QOL is most likely to fit the novice and complementary archetype. Thus, it is likely that reinforcement about routine self-care behaviors as well as what to do when symptoms occur is necessary for both the patient and caregiver. In contrast, patients with really poor QOL and greater limitations to activities of daily living and those with the best relationship to their caregivers are most likely to fit the expert and collaborative archetype. It is likely that this type of dyad has already optimized what they can do with respect to their contributions to self-care because heart failure related QOL is so poor despite exceptional self-care. At some point, the progressive nature of heart failure becomes refractory even to expert level self-care (Lee et al., 2011). Thus, optimized medical management or advanced therapies and care planning may be necessary for this type of heart failure dyad.

\subsection{Strengths and limitations}

There are several limitations of our work that need to be considered when interpreting these results. First, self-care behaviors are not well understood among Italian adults with heart failure, and there are both cultural and healthcare system aspects that must be taken into account. For example, Italian patients with heart failure are better at adhering to prescribed medical therapies than they are to monitoring for signs of worsening heart failure or responding to symptoms when they occur (Cocchieri et al., 2014). Heart failure clinics are not as ubiquitous in Italy compared with other European and distant nations; thus, self-titration of diuretics dosing in response to edema or dyspnea is uncommon (Cocchieri et al., 2014). There also have been noted deficiencies in the standards of heart failure care in Italy because many patients with heart failure receive the majority of their care from general practitioners (Cancian et al., 2013). Thus, we cannot comment on the cultural-specificity of these finding that may or may not generalize to all heart failure subpopulations. Second, this was an analysis of crosssectional data on patients and their primary caregivers who were relatively healthy and well compared with other studied heart failure dyads. Thus, we cannot comment on the changing nature of dyadic contributions to heart failure self-care or how these distinct patterns are related to changes in factors like QOL, caregiver strain, or healthcare utilization over time. Third, because of the wording of the CC-SCHFI, we are not able to tease out whether caregivers are engaged in recommending selfcare behaviors or the actual conduct of the behaviors on behalf of the heart failure patients themselves.

There are also several notable strengths of our work. First, we took a dyadic approach to address our research question that included patient-, caregiver-, and dyadiclevel factors. Second, our use of multilevel modeling to generate dyadic averages and quantify incongruence between the caregivers' and patients' respective contributions to care is a robust method to handle the interdependence of these data and allowed us to integrate both of these metrics into our approach to data clustering. A third strength is our broad inclusion of caregivers, not just spousal dyads, who represented a large sample with a good mixture of genders on the part of the patients and caregivers. Finally, we used latent class mixture modeling 
to identify naturally occurring archetypes of dyadic contributions to heart failure self-care, and incorporated multivariate statistics to identify additional archetypal determinants. Clearly, there is more research needed in the area of dyadic contributions to heart failure care, including studying specific behaviors and studying them across time.

\section{Conclusions}

We observed three distinct archetypes of dyadic contributions to heart failure self-care among Italian heart failure patients and their primary caregivers. Considering these specific dyadic archetypes may enable more tailored interventions to augment heart failure self-care within the context of how patients and their caregivers work together to manage heart failure.

\section{Conflict of interest: None declared.}

Funding: No external funding.

Ethical approval: This study complied with the Declaration of Helsinki, ethics committees at each site approved the research protocol, and informed consent was obtained from all participants. To ensure compliance with de-identified data handling procedures, the secondary analysis presented in this paper was also reviewed by the Institutional Review Board of the first and several other authors; the analysis was deemed as being exempt for human subjects review as all data were appropriately de-identified.

\section{Acknowledgements}

The authors acknowledge the Center of Excellence for Nursing Scholarship, Rome, for funding the parent study. The sponsor of the parent study did not have any role in the current analysis.

\section{Appendix A. Supplementary data}

Supplementary data associated with this article can be found, in the online version, at http://dx.doi.org/10.1016/ j.ijnurstu.2014.11.005.

\section{References}

Berg, C.A., Upchurch, R., 2007. A developmental-contextual model of couples coping with chronic illness across the adult life span. Psychol. Bull. 133 (6), 920-954

Buck, H.G., Harkness, K., Wion, R., Carroll, S.L., Cosman, T., Kaasalainen, S. Kryworuchko, J., McGillion, M., O'Keefe-McCarthy, S., Sherifali, D. Strachan, P.H., Arthur, H.M., 2014. Caregivers' contributions to heart failure self-care: a systematic review. Eur. J. Cardiovasc. Nurs., [Epub ahead of print]

Buck, H.G., Kitko, L., Hupcey, J.E., 2013. Dyadic heart failure care types: qualitative evidence for a novel typology. J. Cardiovasc. Nurs. 28 (6), E37-E46.

Cancian, M., Battaggia, A., Celebrano, M., Del Zotti, F., Novelletto, B.F., Michieli, R., Saugo, M., Pellizzari, M., Toffanin, R., 2013. The care for chronic heart failure by general practitioners. Results from a clinical audit in Italy. Eur. J. Gen. Pract. 19 (1), 3-10.

Charlson, M.E., Pompei, P., Ales, K.L., MacKenzie, C.R., 1987. A new method of classifying prognostic comorbidity in longitudinal studies: development and validation. J. Chronic Dis. 40 (5), 373-383.
Cocchieri, A., Riegel, B., D’Agostino, F., Rocco, G., Fida, R., Alvaro, R., Vellone, E., 2014. Describing self-care in Italian adults with heart failure and identifying determinants of poor self-care. Eur. J. Cardiovasc. Nurs., [Epub ahead of print].

Dalteg, T., Benzein, E., Fridlund, B., Malm, D., 2011. Cardiac disease and its consequences on the partner relationship: a systematic review. Eur. J. Cardiovasc. Nurs. 10, 140-149.

Dickson, V.V., Deatrick, J.A., Riegel, B., 2008. A typology of heart failure self-care management in non-elders. Eur. J. Cardiovasc. Nurs. 7 (3), $171-181$.

Folstein, M.F., Folstein, S.E., McHugh, P.R., 1975. Mini-mental state. A practical method for grading the cognitive state of patients for the clinician. J. Psychiatr. Res. 12 (3), 189-198.

Heidenreich, P.A., Albert, N.M., Allen, L.A., Bluemke, D.A., Butler, J., Fonarow, G.C., Ikonomidis, J.S., Khavjou, O., Konstam, M.A., Maddox, T.M., Nichol, G., Pham, M., Pina, I.L., Trogdon, J.G., 2013. Forecasting the impact of heart failure in the United States: a policy statement from the American Heart Association. Circ. Heart Fail. 6 (3), 606-619.

Hwang, B., Fleischmann, K.E., Howie-Esquivel, J., Stotts, N.A., Dracup, K., 2011. Caregiving for patients with heart failure: impact on patients' families. Am. J. Crit. Care 20 (6), 431-441, quiz 442.

Jaarsma, T., Stromberg, A., Ben Gal, T., Cameron, J., Driscoll, A., Duengen, H.D., Inkrot, S., Huang, T.Y., Huyen, N.N., Kato, N., Koberich, S., Lupon, J., Moser, D.K., Pulignano, G., Rabelo, E.R., Suwanno, J., Thompson, D.R., Vellone, E., Alvaro, R., Yu, D., Riegel, B., 2013. Comparison of self-care behaviors of heart failure patients in 15 countries worldwide. Patient Educ. Couns. 92 (1), 114-120.

Janssen, D.J., Spruit, M.A., Wouters, E.F., Schols, J.M., 2012. Symptom distress in advanced chronic organ failure: disagreement among patients and family caregivers. J. Palliat. Med. 15 (4), 447-456.

Lee, C.S., Moser, D.K., Lennie, T.A., Tkacs, N.C., Margulies, K.B., Riegel, B., 2011. Biomarkers of myocardial stress and systemic inflammation in patients who engage in heart failure self-care management. J. Cardiovasc. Nurs. 26 (4), 321-328.

Luttik, M.L., Blaauwbroek, A., Dijker, A., Jaarsma, T., 2007. Living with heart failure: partner perspectives. J. Cardiovasc. Nurs. 22, 131-137.

Luttik, M.L., Jaarsma, T., Veeger, N., Tijssen, J., Sanderman, R., van Veldhuisen, D.J., 2007. Caregiver burden in partners of Heart Failure patients; limited influence of disease severity. Eur. J. Heart Fail. 9 (6-7), 695-701.

Lyons, K.S., Zarit, S.H., Sayer, A.G., Whitlatch, C.J., 2002. Caregiving as a dyadic process: perspectives from caregiver and receiver. J. Gerontol. Psychol. Sci. 57B, P195-P204.

Mahoney, F.I., Barthel, D.W., 1965. Functional evaluation: the Barthel Index. Md. State Med. J. 14, 61-65.

McMurray, J.J., Adamopoulos, S., Anker, S.D., Auricchio, A., Bohm, M., Dickstein, K., Falk, V., Filippatos, G., Fonseca, C., Gomez-Sanchez, M.A., Jaarsma, T., Kober, L., Lip, G.Y., Maggioni, A.P., Parkhomenko, A., Pieske, B.M., Popescu, B.A., Ronnevik, P.K., Rutten, F.H., Schwitter, J., Seferovic, P., Stepinska, J., Trindade, P.T., Voors, A.A., Zannad, F., Zeiher, A., Bax, J.J., Baumgartner, H., Ceconi, C., Dean, V., Deaton, C., Fagard, R., Funck-Brentano, C., Hasdai, D., Hoes, A., Kirchhof, P., Knuuti, J., Kolh, P., McDonagh, T., Moulin, C., Reiner, Z., Sechtem, U., Sirnes, P.A., Tendera, M., Torbicki, A., Vahanian, A., Windecker, S., Bonet, L.A., Avraamides, P., Ben Lamin, H.A., Brignole, M., Coca, A., Cowburn, P., Dargie, H., Elliott, P., Flachskampf, F.A., Guida, G.F., Hardman, S., Iung, B., Merkely, B., Mueller, C., Nanas, J.N., Nielsen, O.W., Orn, S., Parissis, J.T., Ponikowski, P., 2012. ESC guidelines for the diagnosis and treatment of acute and chronic heart failure 2012: The Task Force for the Diagnosis and Treatment of Acute and Chronic Heart Failure 2012 of the European Society of Cardiology. Developed in collaboration with the Heart Failure Association (HFA) of the ESC. Eur. J. Heart Fail. 14 (8), 803-869.

Moser, D.K., Dickson, V., Jaarsma, T., Lee, C., Stromberg, A., Riegel, B., 2012. Role of self-care in the patient with heart failure. Curr. Cardiol. Rep. 14 (3), 265-275

Najafi, F., Jamrozik, K., Dobson, A.J., 2009. Understanding the 'epidemic of heart failure': a systematic review of trends in determinants of heart failure. Eur. J. Heart Fail. 11 (5), 472-479.

Novak, M., Guest, C., 1989. Application of a multidimensional caregiver burden inventory. Gerontologist 29 (6), 798-803.

Pressler, S.J., Gradus-Pizlo, I., Chubinski, S.D., Smith, G., Wheeler, S., Sloan, R., Jung, M., 2013. Family Caregivers of Patients With Heart Failure: A Longitudinal Study. J. Cardiovasc. Nurs. 28 (5), 417-428.

Quinn, C., Dunbar, S.B., Higgins, M., 2010. Heart failure symptom assessment and management: can caregivers serve as proxy? J. Cardiovasc. Nurs. 25, 142-148.

Ram, N., Grimm, K.J., 2009. Methods and measures: growth mixture modeling: a method for identifying differences in longitudinal 
change among unobserved groups. Int. J. Behav. Dev. 33 (6), 565576.

Rector, T.S., Kubo, S.H., Cohn, J.N., 1993. Validity of the Minnesota Living with Heart Failure questionnaire as a measure of therapeutic response to enalapril or placebo. Am. J. Cardiol. 71 (12), 1106-1107.

Retrum, J.H., Nowels, C.T., Bekelman, D.B., 2013. Patient and caregiver congruence: the importance of dyads in heart failure care. J. Cardiovasc. Nurs. 28, 129-136.

Riegel, B., Lee, C.S., Albert, N., Lennie, T., Chung, M., Song, E.K., Bentley, B., Heo, S., Worrall-Carter, L., Moser, D.K., 2011. From novice to expert: confidence and activity status determine heart failure self-care performance. Nurs. Res. 60 (2), 132-138.

Riegel, B., Lee, C.S., Dickson, V.V., 2011. Self care in patients with chronic heart failure. Nat. Rev. Cardiol. 8 (11), 644-654.

Riegel, B., Moser, D.K., Anker, S.D., Appel, L.J., Dunbar, S.B., Grady, K.L. Gurvitz, M.Z., Havranek, E.P., Lee, C.S., Lindenfeld, J., Peterson, P.N. Pressler, S.J., Schocken, D.D., Whellan, D.J., 2009. State of the science: promoting self-care in persons with heart failure: a scientific statement from the American Heart Association. Circulation 120 (12), $1141-1163$.

Rohrbaugh, M.J., Mehl, M.R., Shoham, V., Reilly, E.S., Ewy, G.A., 2008. Prognostic significance of spouse we talk in couples coping with heart failure. J. Consult. Clin. Psychol. 76, 781-789.
Sebern, M., Riegel, B., 2009. Contributions of supportive relationships to heart failure self-care. Eur. J. Cardiovasc. Nurs. 8, 97-104.

Sebern, M.D., Woda, A., 2012. Shared care dyadic intervention: outcome patterns for heart failure care partners. West. J. Nurs. Res. 34 (3), 289316.

Vellone, E., Chung, M.L., Cocchieri, A., Rocco, G., Alvaro, R., Riegel, B., 2014. Effects of self-care on quality of life in adults with heart failure and their spousal caregivers: testing dyadic dynamics using the actorpartner interdependence model. J. Fam. Nurs. 20 (1), 120-141.

Vellone, E., Riegel, B., Cocchieri, A., Barbaranelli, C., D’Agostino, F., Antonetti, G., Glaser, D., Alvaro, R., 2013. Psychometric testing of the self-care of heart failure index version 6.2. Res. Nurs. Health 36 (5), 500-511.

Vellone, E., Riegel, B., Cocchieri, A., Barbaranelli, C., D'Agostino, F., Glaser, D., Rocco, G., Alvaro, R., 2013. Validity and reliability of the caregiver contribution to self-care of heart failure index. J. Cardiovasc. Nurs. 28 (3), 245-255.

von Elm, E., Altman, D.G., Egger, M., Pocock, S.J., Gotzsche, P.C., Vandenbroucke, J.P., 2007. The Strengthening the Reporting of Observational Studies in Epidemiology (STROBE) statement: guidelines for reporting observational studies. Epidemiology 18 (6), 800-804.

Ware Jr., J., Kosinski, M., Keller, S.D., 1996. A 12-Item Short-Form Health Survey: construction of scales and preliminary tests of reliability and validity. Med. Care 34 (3), 220-233. 